\title{
Empowering caregivers of children with learning and developmental disabilities: from situation analysis to community-based inclusive development in Kilifi, Kenya
}

Karen Bunning, Joseph Karisa Gona, Charles Richard Newton and Sally Hartley

\begin{abstract}
Purpose - Raising a child with learning and developmental disabilities in a low-income setting is challenged by inadequate resources, limited support and poverty. The impacts on caregivers include fatigue, distress and isolation. The purpose of this paper is to report on a programme (2008-2021) that was set up in Kilifi County, Kenya to investigate and address these difficulties.
\end{abstract}

Methodology - The programme used mixed methods through a series of interconnected studies, starting with a situation analysis, followed by a home-based intervention where the caregiver served as agent for change using augmentative and alternative communication (AAC) methods. This was followed by two community-based inclusive development initiatives: disability awareness training to community groups and empowering self-help groups for caregivers of children growing up with disabilities.

Findings - The situation analysis revealed scarce support services for caregivers and children with learning and developmental disabilities, with report of limited resources, inadequate coverage and poor professional practice. A home-based, AAC intervention was associated with improved caregiver wellbeing, significant positive changes to caregiver perceptions of the child's communication and some expansion to the child' social activities. However, questions around sustainability persisted. Disability awareness training led by persons with lived experience of disability showed positive changes to the views, values and attitudes of established community groups. Caregiver participation in self-help groups was associated with their greater personal agency, perceptions of increased social support and reduced severity of child's disability.

Originality - The programme narrative demonstrates a rationalised and evidence-based process for community-based inclusive development that is low cost, culturally acceptable, with potential for sustainability.

Keywords Low-income, Caregivers, Developmental disabilities, Community

Paper type Research paper

\section{Background}

Globally, the development potential of children growing up with disabilities continues to be neglected. A decade ago, the World Report on Disability estimated that $80 \%$ of the 150 million children with disability worldwide were to be found in resource-poor regions of the world (WHO, 2011). The link between disability and poverty has been established unequivocally, particularly in low to middle income countries (LMICs) (Banks et al., 2018). More recent estimates report that $95 \%$ of 52.9 million children below five years with developmental and learning disabilities reside in LMICs. Proportionally, countries in subSaharan Africa contribute about 45\% to this figure (Bitta et al., 2017). Compared to similar
(Information about the authors can be found at the end of this article.)

\footnotetext{
(c) Karen Bunning,

Joseph Karisa Gona, Charles Richard Newton and Sally Hartley.Published by Emerald Publishing Limited. This article is published under the Creative Commons Attribution (CC BY 4.0) licence. Anyone may reproduce, distribute, translate and create derivative works of this article (for both commercial and non-commercial purposes), subject to full attribution to the original publication and authors. The full terms of this licence may be seen at http:// creativecommons.org/licences/ by/4.0/legalcode

The authors would like to express gratitude to the CP Trust for their continued support for our work; to the caregivers who work so tirelessly in meeting the challenges associated with supporting a child with developmental and learning disabilities; to KEMRI, and to Kuhenza for the Children Foundation for hosting this work.
} 
estimates in 1990, the lack of significant improvement to the burden of developmental disabilities has been highlighted (Olusanya, 2018).

Most people residing in sub-Saharan African countries experience a reduced standard of living compared to those living in high-income countries, characterised by inadequate access to health provision (Peters et al., 2008), low school attendance (Kuper et al., 2014), limited employment rates and low wages (Mizunoya and Mitra, 2012). However, lower educational and labour market outcomes are more likely amongst those with disabilities than those without (Trani et al., 2011). Furthermore, families of children with disabilities tend to spend more on health care than those without disabled members (Mitra et al., 2011). In Sierra Leone, families with a child with severe disabilities spend on average of 1.3 times more on health care than families without a person with a disability (Trani et al., 2011). Less than 10\% of children with disabilities were reported as attending school in Africa (UNESCO, 2015).

In terms of support, there is wide variation in health, education and social services, across the African continent. Rehabilitation services that exist tend to be clustered around urbanbased institutions with report of serious limitations in coverage and capacity (Njelesani et al., 2011). The problems are aggravated by deficiencies in workforce and the availability of up-to-date practical equipment, for example in Ghana (Tinney et al., 2007) and Tanzania (Njelesani et al., 2011), and indeed across sub-Saharan Africa (Adugna et al., 2020). Nongovernment funded organisations provide a source of support (WHO, 2011) but are subject to similar financial and resource constraints. Uptake of services is affected by limited access at a community level, particularly in rural areas where families are affected by inadequate transport systems (Moisi et al., 2011).

Typically, it is the mother or grandmother who assumes the role of primary caregiver responsible for the child's development and welfare in contexts of limited support and scarce resources (Zuurmond et al., 2019). These challenges are compounded by community attitudes and beliefs espoused in relation to disability. Across sub-Saharan Africa, disability has been explained in relation to superstitious circumstances that give rise to stigma and discrimination, both in the immediate family and in the local community (Adugna et al., 2020); for example breach of social conventions (e.g. incestuous relations between family members) in Botswana (Shumba and Abosi, 2011), Ghana (Antony, 2011) and Kenya (Bunning et al., 2017); and preternatural forces in Malawi (Paget et al., 2016), Namibia (Haihambo and Lightfoot, 2010) and Kenya (Bunning et al., 2017). The impacts on the caregiver include psychological distress and social isolation, fatigue and mental health crises in some cases (Masulani-Mwale et al., 2016).

Disparities exist between regions of the world in how primary diagnoses are established for children growing up with a disability. Health-care systems in high-income countries support the early diagnosis and intervention with such children. The reverse is often the case in resource-poor regions of the world attributed to "lack of availability of continuous care, inadequate training and experience of health care providers and insufficient secondaryand tertiary-level health centres" (Ertem, 2012, p. 13). Regardless of the child's primary diagnosis, similar challenges are experienced by children, caregivers and families in lowincome countries. Thus, the research and development programme presented in this paper does not discriminate between the different conditions affecting development and adopts the inclusive term "developmental disabilities". The aim of this paper is to provide a critical narrative to a research and development programme that moves from an understanding of the existing situation for caregivers and their children with developmental disabilities, towards intervention approaches that build on the assets of the community.

\section{Research and development programme}

Building on existing connections between University of East Anglia (UEA) and the Kenya Medical Research Institute (KEMRI), we managed a research and development programme 
in Kilifi County, Kenya (2008 to present). Figure 1 provides an illustration of the direction taken: from situation analysis to community-based inclusive development. The main aim was to identify and address the gaps in pre-existing knowledge and establish intervention practice with in-built cultural relevance and sustainability.

\section{Setting}

Situated in the coastal region of Kenya, Kilifi County is one of the poorest areas in Kenya, with a $71.4 \%$ poverty level, with most residents living in dwellings of mud construction consisting of one or two rooms, with no power supply or running water. Pre-Covid, per capita, the average income for a family (parents and six children) was KES1000 per month - less than US\$13 (Kenya National Bureau for Statistics, 2015). Families are largely dependent on subsistence farming for income. Kilifi residents are mainly from the Mijikenda groups (about $80 \%$ ) and speak Swahili, Giriama and Chonyi. A county-wide survey of neurological impairment in children aged 6-9years revealed a $6.1 \%$ prevalence for moderate-severe difficulties (Munga'la-Odera et al., 2006).

Ethical approval for each study was given by the Scientific Ethics and Review Unit (SERU) in Nairobi, Kenya and the International Development Ethics Committee at University of East Anglia, UK.

\section{Situation analysis}

To establish the nature, availability and coverage of support for children with disabilities (0-15 years) and their families, a situation analysis was conducted between 2008 and 2011. This included a descriptive and record-based survey of service provision and utilisation

\section{Figure 1 Summary of Kenya-based programme from situation analysis, through home-} based intervention, to community-based inclusive development

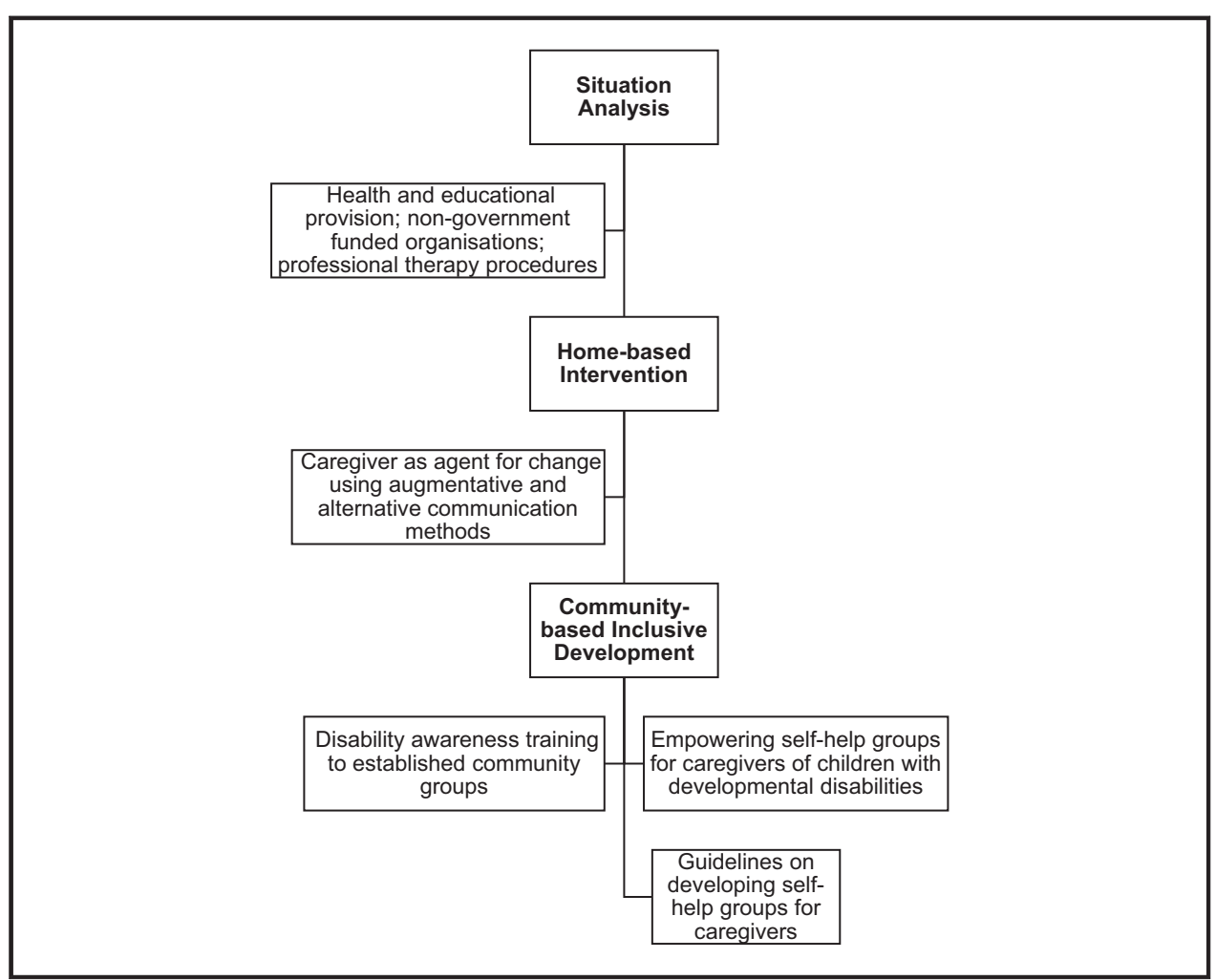


within the health rehabilitation and special education sectors, key informant interviews with staff and structured observation of rehabilitation sessions designated as "speech therapy". Our findings revealed workforce deficiencies in health and educational provision, poor attendance of appointments by caregivers and their children, poor access at a community level compounded by inadequate transport systems (Bunning et al., 2014a, 2014b, Gona, 2014) and sub-optimal practice in the area of therapy for promoting speech, language and communication development (Bunning et al., 2013). One important finding to emerge was the relationship between the caregiver and the child characterised by supportive communication, such as shared use of gesture and self-expression. This led us to consider caregivers as agents for change in the lives of their children with disabilities.

\section{Home-based intervention}

To investigate the potential role of caregivers, a home-based intervention using augmentative and alternative communication methods was piloted with children with complex communication needs associated with learning and developmental disabilities (2011-2013). A stratified sample of children representing the main disability groups (learning disabilities; cerebral palsy; deafness; autism; multiple disabilities) was recruited, together with the relevant primary caregivers, e.g. typically the mother or grandmother. Pre- and post-intervention measures included interviews with caregivers and administration of the Communication Disability Profile. The latter was developed as an outcome measure in neighbouring Uganda (Baker and Hartley, 1998), which frames communication around the domains of the International Classification of Functioning, Disability and Health (e.g. body function and structure; activity; participation) (WHO, 2002). The intervention was devised to be:

- technically valid such that it could be used in the home context;

- economically feasible and requiring neither power supply or technical expertise; and

- socially and culturally acceptable (Alant, 2005).

Based on the pre-intervention measures and observations in situ, a tailored communication plan was established for each child. The design of the interventions drew on the professional skills of the first author $(\mathrm{KB})$ who has a background in speech and language therapy, and the second author (JKG), who was formerly a teacher of special education needs, specialising in education of deaf and hearing-impaired children. Locally sourced materials were purchased (e.g. objects of reference, multi-sensory items, photographic images) or made (e.g. a board was made for displaying objects of reference). Their usage was demonstrated to the caregiver by JKG in the language of the home. The caregivers demonstrated the ability to carry out the intervention. Post-intervention gains included a greater sense of well-being among the caregivers (Authors et al., 2013), who perceived their child's disability as less severe with a reported increase in the child's community participation (Bunning et al., 2014a, 2014b, Gona, 2014). Despite such positive outcomes, sustainability of approach was a concern because the intervention design relied on the professional skills of the researchers and a small budget to purchase AAC materials locally. Furthermore, the potential for scaling up an intervention that depended on professional input within limited resources was an issue. Therefore, we shifted our focus to communityinitiated approaches.

\section{Community-based inclusive development}

To draw on the assets of the wider community, we moved beyond the home and adopted community-based inclusive development (CBID), formerly community-based rehabilitation (CBR), a composite strategy for meeting the needs of persons with disabilities (WHO, 2010). Divided into five key domains, it offers guidance on community-based initiatives by focusing on health, education, livelihood, social and empowerment (WHO, 2010). 
Firstly, to investigate cultural understanding of disability and the associated challenges for caregivers, we conducted focus group discussions with 21 established community groups (women groups; community health worker groups). This revealed a melting pot of superstitious beliefs (e.g. the advent of disability associated with witchcraft, demons and evil spirits), misconceptions about disability causation, discriminatory attitudes and aversive responses (e.g. attributing environmental disasters such as a lack of rains to the person with a disability and their family) (Bunning et al., 2017). Secondly, to raise awareness of issues and to shape community responses to persons with disability, we focused on the "empowerment" domain for its cross-cutting potential to the four other domains (WHO, 2010). We employed four local people with lived experience of disability (with cerebral palsy, autism, learning disabilities and deafness) as "trainers". Supported by a series of preparatory meetings, the "trainers" were encouraged to develop the telling of their personal story, using drama, mime, hand and body gesture and words. They shared their personal stories with 20 established community groups (health community workers and women groups), each with around 10-15 members. Focus groups discussions were carried out with each community group pre- and post-intervention. Framework analysis revealed a shift in the psychological constructs underpinning group attitudes towards persons with a disability - from viewing them as a "burden" to individuals with "agency"; and from "sub-human" to "human" (Gona et al., 2018). At project closure, it was the community groups who campaigned for further action to improve the lives of people living with disability.

We adjusted our focus to the caregivers and their children with learning and developmental disabilities (2015-2018). Staying with the "empowerment" domain of the CBID/CBR (WHO, 2010), we identified self-help groups (SHGs) as the primary vehicle for change. Founded on peer collaboration, rather than professional support, the emphasis was on psychological empowerment. The aim was to support the caregivers to gain control over their lives with no expectation of professional input from the already constrained rehabilitation services.

For this purpose, we adopted a realist evaluation research design, which recognises the variable ways interventions work across individuals and contexts because it recognises that change is affected by context (Pawson and Tilley, 1997). The 20 community groups from the previous study mobilised 254 caregivers to form 20 SHGs. Set-up of the groups occurred over a 10-month period. During this time, the groups met weekly. Researcher monitoring visits occurred at monthly intervals, providing opportunities for problem solving and advice as appropriate. The groups were encouraged to start up various income generation activities, including "merry-go-round" (where group members contribute small sums of money or food items at each meeting, which are allocated to two or three individuals for family use and income development by rotation so each member has a turn as a beneficiary); farming; and livestock rearing. At the end of the set-up phase, 11 groups remained comprising 154 caregivers - nine groups having dissolved variously due to drought conditions, in-group tensions and fraudulent activity in the local community (Bunning et al., 2020, Gona, 2020).

We carried out a facilitated intervention with the 11 groups that were functioning at the end of the set-up period. Run as a series of interactive workshops, six sessions were delivered to each group at monthly intervals covering topics of economic empowerment; speaking about own personal situation; peer support; community inclusion; access to health; and access to education.

Evaluation involved focus group discussions with each group before and after the facilitated intervention. We also administered two questionnaires to a sample of 75 caregivers: Sub-sections of the Communication Disability Profile (Baker and Hartley, 1998) as summarised previously; and he Multi-dimensional Scale of Perceived Social Support (Zimet et al., 1988). All the measures were administered in the preferred language of the participants (i.e. Swahili and Giriama). At baseline the caregivers' experiences were defined by a sense of "burden" that was characterised by "aloneness", "challenges", "stigma" and "discrimination". Post-intervention, caregiver "agency" 
emerged emphatically and illustrated their sense of "togetherness", "capacity-building", "acceptance" and "well-being". There were significant gains in the caregiver's social support networks; they viewed their child's disability as less severe, and their caregiving role as less problematic. Mechanisms of "handling goods and money" and "social ties and support" were determined to underpin the outcomes (Bunning et al., 2020, Gona, 2020).

\section{Guidelines}

Based on the development of empowering self-help groups, we devised some practical guidelines to extend the uptake of this work. The guidelines draw on earlier work by Zimmerman (1995) and are centred on the empowerment process. The guidelines focus on three key domains:

1. The way you think about yourself: If you encounter difficulties bringing up a child with disabilities, if you are tired and sad, if you feel all alone with your worries, you can feel bad about yourself and helpless. Part of being empowered is feeling good about yourself.

2. The way you communicate with other people: If you fear what other people will say and how they will react to your child, if you stay with your child at home - not communicating with other people around you, you can feel isolated and unsure. Part of being empowered is speaking up for yourself.

3. The way you act to bring changes to your life: This means taking action yourself, instead of waiting for something to happen. Sometimes the difficulties you face in life can feel over-whelming. You may feel helpless - not knowing what to do. You may feel that you have no say or control over your circumstances. The final part of being empowered is being able to bring about change.

The guidelines proceed through various sections on: setting up a self-help group; building resources and activities; facilitating group discussions on relevant topics; microfinance opportunities for groups to grow their income generating projects; and evaluating a selfhelp group. The guidelines were presented to interested registrants at the Africa Network CBR Conference in Zambia, 2018. In total, 37 sites across 10 countries, signing up to trial the SEEK guidelines. Proposals included self-help groups for parents at primary schools (Malawi); capacity-building for disabled persons organisations (Zambia); enhancement of existing caregiver support programmes (Ethiopia; DRC). Implementation has been impacted by the global pandemic. However, early feedback from Zambia referred to "strengthening the parent support groups to become self-sustaining", empowering "children to learn how to make doormats, sew bags and string beads into necklaces and bracelets" with reported impacts of mutual support, growth in confidence and vocational planning for children with disabilities.

\section{Follow-up}

In the first year of follow-up (2018-2019), the economic benefits of SHG livelihood projects were evident in group bank statements. In focus group discussions at one-year follow-up, the caregivers spoke of their savings and the extra resources for their children with disabilities, e.g. food, skin oil and well-being. This is captured in the testimony of one caregiver:

I'm happy because my child with disability cannot cry for anything now. I can provide for him with what I get from this group. It has brought us together. We all have phones and we can communicate with each other in case there is need. 
The groups told of their plans for business and reported how all their children with disabilities attended school with the exceptions of a few where transport was a barrier to access.

Just before COVID-19 lockdown (01.02.20), the caregivers expressed high satisfaction in their roles in relation to their children with disabilities, with a positive sense of their own value and personal growth. The groups were progressing their ambitions in terms of income generation, bank account savings, social connections with each other and their aspirations and plans for the future. Money worries and a lack of caregiver support were still present; however, there was new confidence in their ability to manage. In early 2020, the advent of COVID-19 affected the people across the globe. Despite the isolation imposed by lockdown, contact among the membership has been maintained via brief socially distanced meetings and mobile phone communications. The groups have been active in identifying and advocating for the needs of their most vulnerable members, with representations being made to the local Chief's office for food relief. However, group progress has been negatively affected. Local lockdowns impacted group meetings, access to markets for selling produce, travel and school attendance for the children. Other factors such as the lack of rains, floods, avian flu affecting poultry, dishonesty among the membership and broader community, variously affected the groups during this period. Nevertheless, the infrastructure of the self-help groups appears to have mitigated against the worst effects of the pandemic by facilitating contact and mutual support among the membership.

\section{Conclusions}

The situation faced by many children and adults with learning and developmental disabilities in LMICs is one of limited financial and material resources, deficient professional support characterised by workforce limitations and poor coverage. At a community level, accessing support is affected by an inadequate transportation system, distance from the urban locations of health and educational facilities and the negative attitudes shown towards individuals with disabilities and their families. The primary caregiver, typically the mother, bears the major responsibility for looking after and supporting a child growing up with learning and developmental disabilities. Feelings of isolation and psychological distress, fatigue and mental health crises in some cases are not uncommon.

Community-based inclusive development initiatives offer some practical and low-cost routes towards mediating some of the challenges experienced by caregivers and their children with learning and developmental disabilities. New roles are assumed by key stakeholders including: people with lived experience of disabilities as trainers and advocates; caregivers as contributors to the livelihood of their groups and families, as members of a social support network and as individuals who can change the outcomes for their children with learning and developmental disabilities.

The current programme of studies focuses on caregivers and children with developmental disabilities in Kilifi County, Kenya and provides an illustration of the current situation in this setting and the outcomes associated with applied intervention approaches. There is a need for larger scale investigations and applications of community-based initiatives across multiple settings, where the challenges of caring for a child with developmental disabilities exist.

Beyond the low-income countries of the world, is it possible that CBID offers potential opportunities for the support and development of individuals with learning disabilities across the life course and their families? In circumstances of constrained health and social support resources, where the availability of professional support services (e.g. school, residential home) is impacted, middle- and high-income countries might benefit from community-based approaches. Some initiatives already exist, such as the network of parent-led support groups through the Down's Syndrome Association (www.downs- 
syndrome.org.uk/about-dsa/our-network/local-support-groups/). As we emerge from the COVID-19 pandemic with new financial challenges facing statutory health and social services, perhaps now is the time for community-based inclusive developments.

\section{References}

Adugna, M.B., Nabbouh, F., Shehata, S. and Ghaharo, S. (2020), "Barriers and facilitators to healthcare access for children with disabilities in low and Middle income Sub-Saharan African countries: a scoping review", BMC Health Services Research, Vol. 20 No. 1, p. 15, doi: 10.1186/s12913-019-4822-6.

Alant, E. (2005), "AAC technology for development", Alant, E. and Lloyd, L. (Eds), Augmentative and Alternative Communication and Severe Disabilities: Beyond Poverty, Whurr Publishers, London, pp. 192-220.

Baker, H. and Hartley, S. (1998), "Designing a communication ability outcome measuring tool", unpublished master's thesis, Centre of International Child Health, University of London.

Banks, L.M., Kuper, H. and Polack, S. (2018), "Poverty and disability in low- and middle-income countries: a systematic review", PLOS ONE, Vol. 12, available at: https://doi.org/10.1371/journal.pone. 0189996

Bitta, M., Karuki, S., Abubakar, A. and Newton, C. (2017), "Burden of neurodevelopmental disorders in low and middle-income countries: a systematic review and Meta-analysis", Wellcome Open Research, Vol. 2, p. 121, doi: 10.12688/wellcomeopenres.13540.1.

Bunning, K., Gona, J., Newton, C. and Hartley, S. (2017), "The perception of disability by community groups: stories of local understanding, beliefs and challenges in a rural part of Kenya", PLOS ONE, Vol. 12 No. 8, doi: 10.1371/journal.pone.0182214.

Bunning, K., Gona, J.K., Newton, C.R. and Hartley, S. (2014a), "Caregiver perceptions of children who have complex communication needs following a home-based intervention using augmentative and alternative communication in rural Kenya: an intervention note", Augmentative and Alternative Communication, Vol. 30 No. 4, pp. 344-356, available at: https://doi.org/10.3019/07434618.2014.970294.

Bunning, K., Gona, J., Buell, S., Newton, C. and Hartley, S. (2013), "Investigation of practices to support the complex communication needs of children with hearing impairment and cerebral palsy in a rural district of Kenya", International Journal of Language \& Communication Disorders, Vol. 48, pp. 689-702, doi: 10.1111/1460-6984.12042.

Bunning, K., Gona, J.K., Odera-Mung'ala, V., Newton, C., Geere, J., Hong, C.S. and Hartley, S. (2014b), "Survey of rehabilitation support for children 0-15 years in a rural part of Kenya", Disability \& Rehabilitation, Vol. 36 No. 12, pp. 1033-1041, available at: https://doi.org/10.3109/09638288.2013.829524.

Bunning, K., Gona, J.K., Newton, C.R., Andrews, F., Blazey, C., Ruddock, H., Henery, J. and Hartley, S. (2020a), "Empowering self-help groups for caregivers of children with disabilities in Kilifi, Kenya: impacts and their underlying mechanisms", PLOS ONE, Vol. 15 No. 3, available at: https://doi.org/10.1371/journal. pone.0229851

Ertem, I.O. (2012), Developmental difficulties in early childhood: prevention, early identification, assessment and intervention in low and middle-income countries: a review. World Health Organization, Geneva, available at: https://apps.who.int/iris/bitstream/handle/10665/97942/9789241503549_eng.pdf? sequence $=1$ \&isAllowed $=y$ (accessed 03 August 2021).

Gona, J.K., Newton, C.R., Hartley, S. and Bunning, K. (2014), "A home-based intervention using augmentative and alternative communication (AAC) techniques in rural Kenya: what are the carers' experiences?", Child: Care, Health, and Development, Vol. 40 No. 1, pp. 29-41, doi: 10.1111/cch.12031.

Gona, J.K., Newton, C.R., Hartley, S. and Bunning, K. (2018), "Person with disabilities as experts-byexperience: using personal narratives to affect community attitudes in Kilifi, Kenya", BMC International Health \& Human Rights, Vol. 18 No. 18, pp. 1-12, available at: https://doi.org/10.1186/s12914-018-0158-2

Gona, J.K., Newton, C.R., Hartley, S. and Bunning, K. (2020), "Development of self-help groups for caregivers of children with disabilities in Kilifi, Kenya: process evaluation", African Journal of Disability, Vol. 9 No. 0, doi: https://doi.org/10.4102/ajod.v9i0.650.

Haihambo, C. and Lightfoot, E. (2010), "Cultural beliefs regarding people with disabilities in Namibia: implications for the inclusion of people with disabilities", International Journal of Special Education, Vol. 25, pp. 76-87. 
Kenya National Bureau for Statistics (KNBS), (2015), "Kenya integrated household budget survey", available at: http://statistics.knbs.or.ke/nada/index.php/catalog/88 (accessed 20 July 2021).

Kuper, H., Monteath-van Dok, A., Wing, K., Danquah, L. and Evans, J. (2014), "The impact of disability on the lives of children; cross-sectional data including 8,900 children with disabilities and 898,834 children without disabilities across 30 countries", PLOS ONE, Vol. 9 No. 9, doi: 10.1371/journal.pone.0107300.

Masulani-Mwale, C., Kauye, F., Gladstone, M. and Mathanga, D. (2016), "Parenting children with intellectual disabilities in Malawi: the impact that reaches beyond coping?, child care", Health and Development, Vol. 42 No. 6, pp. 871-880

Mitra, S. Posarac, A. and Vick, B. (2011), "Disability and poverty in developing countries: a snapshot from the world health survey: SP discussion paper no. 1109", The World Bank, Washington, DC, available at: http:// documents.worldbank.org/curated/en/501871468326189306/pdf/625640NWP0110900_PUBLIC00BOX36148 7B.pdf (accessed 20th July 2021).

Mizunoya, S. and Mitra, S. (2012), "Is there a disability gap in employment rates in developing countries?", Cornell University, available at: http://digitalcommons.ilr.cornell.edu/gladnetcollect/562. (accessed 20 June 2021).

Moisi, J.C., Nokes, J.D. and Gatakaa, H. (2011), "Sensitivity of hospital-based surveillance for severe disease: a geographic information system analysis of access to care in Kilifi district, Kenya", Bulletin of the World Health Organization, Vol. 89 No. 2, pp. 102-111.

Munga'la-Odera, V., Meehan, R., Njugana, P., Mturo, M., Alcock, K.J. and Newton, C.R. (2006), "Prevalence and risk factors of neurological disability and impairment in children living in rural Kenya", International Journal of Epidemiology, Vol. 35 No. 3, pp. 683-688.

Njelesani, J., Couto, S. and Cameron, D. (2011), "Disability and rehabilitation in Tanzania: a review of the literature", Disability and Rehabilitation, Vol. 33 Nos 22/23, pp. 2196-2207.

Olusanya, B.O. (2018), "Developmental disabilities among children younger than 5 years in 195 countries and territories, 1990 to 2016: a systematic analysis for the global burden of disease study 2016", The Lancet Global Health, Vol. 6, doi: 10.1016/S2214-109X(18)30309-7.

Paget, A., Mallewa, M., Chinguo, D., Mahabere-Chrambo, C. and Gladstone, M. (2016), "It means you are grounded: caregivers' perspectives on the rehabilitation of children with neurodisability in Malawi", Disability and Rehabilitation, Vol. 38 No. 3, pp. 223-234.

Pawson, R. and Tilley, N. (1997), Realist Evaluation, Sage, London.

Peters, D.H., Garg, A., Bloom, G., Walker, D.G., Brieger, W.R. and Rahman, M.H. (2008), "Poverty and access to health care in developing countries", Annals of the New York Academy of Sciences, Vol. 1136, pp. 161-171.

Shumba, A. and Abosi, O.C. (2011), "The nature, extent and causes of abuse of children with disabilities in schools in Botswana", International Journal of Disability, Development and Education, Vol. 58 No. 4, pp. 373-388.

Tinney, M.J., Chiodi, A., Haig, A. and Wiredu, E. (2007), "Medical rehabilitation in Ghana", Disability \& Rehabilitation, Vol. 29 , pp. 921-927.

Trani, J.F., Browne, J., Kett, M., Bah, O., Morlai, T., Bailey, N. and Groce, N. (2011), "Access to healthcare, reproductive health and disability: a large-scale survey in Sierra Leone", Social Science \& Medicine, Vol. 73 No. 10, pp. 1477-1489.

UNESCO (2015), "The EFA 2015 global monitoring report. Education for all 2000-2015: achievements and challenges", available at: https://en.unesco.org/gem-report/report/2015/education-all-2000-2015achievements-and-challenges (accessed 20 July 2021).

World Health Organisation (2002), "International classification of functioning, disability and health", Geneva, available at: www.who.int/classifications/international-classification-of-functioning-disabilityand-health (accessed 2 November 2021).

World Health Organisation (2010), "Introductory booklet: CBR guidelines. The world bank", available at: www.who.int/disabilities/cbr/guidelines/en/ (accessed 20 July 2021).

World Health Organisation (2011), "World report on disability, the world bank", available at: www.who.int/teams/ noncommunicable-diseases/sensory-functions-disability-and-rehabilitation/world-report-on-disability (accessed 20 July 2021).

Zimet, G.D., Dahlem, N.W., Zimet, S.G. and Farley, G.K. (1988), "The multidimensional scale of perceived social support”, Journal of Personality Assessment, Vol. 52 No. 1, pp. 30-41. 
Zimmerman, M. (1995), "Psychological empowerment: issues and illustrations", American Journal of Community Psychology, Vol. 23 No. 5, pp. 581-599.

Zuurmond, M., Nyante, G., Baltussen, M., Seeley, J., Abanga, J. and Shakespeare, T. (2019), "A support programme for caregivers of children with disabilities in Ghana: understanding the impact on the wellbeing of caregivers", Child: Care, Health and Development, Vol. 45 No. 1, pp. 45-53.

\section{Further reading}

Anthony, J. (2011), "Conceptualising disability in Ghana: implications for EFA and inclusive education", International Journal of Inclusive Education, Vol. 15 No. 10, pp. 1073-1086, doi: 10.1080/13603116. 2011.555062.

\section{Author affiliations}

Karen Bunning is based at the Faculty of Medicine and Health, University of East Anglia, Norwich, UK.

Joseph Karisa Gona is based at the Walezi Kenya (CBO), Malindi, Kenya.

Charles Richard Newton is based at Centre for Geographic Medicine Research (Coast), Kenya Medical Research Institute, Kilifi, Kenya and Department of Psychiatry, University of Oxford, Oxford, UK.

Sally Hartley is based at the Faculty of Medicine and Health, University of East Anglia, Norwich, UK and The University of Sydney, Sydney, Australia.

\section{Corresponding author}

Karen Bunning can be contacted at: K.Bunning@uea.ac.uk

For instructions on how to order reprints of this article, please visit our website: www.emeraldgrouppublishing.com/licensing/reprints.htm

Or contact us for further details: permissions@emeraldinsight.com 